\title{
Closing editorial
}

\author{
Rodrigo Magalhães ${ }^{1} \cdot$ Henderik A. Proper ${ }^{2}$
}

(c) Springer Nature Switzerland AG 2018

The Organizational Design and Enterprise Engineering (OD\&EE) journal was setup two years ago with the aim to create a bridge between the organizational sciences, management sciences, and the engineering sciences. Even though these domains sometimes "collide" in the real world of companies, industries and organizations, the scientific domains as such seem not to integrate much.

Nevertheless, with a relatively large editorial board with senior researchers who, like us, were convinced of the need to build bridges between the fields, we thought that the OD\&EE journal would be able to quickly create a sufficiently steady flow of submissions.

Regretfully, however, after a first flurry of papers, the flow of papers quickly dried up. Several attempts have been made to further drive the submissions, but to no avail. Special issues linked to events within the relevant communities unfortunately also did not materialize. This has, eventually, resulted in Springer's decision to now shut down the journal.

It is, of course, difficult to clearly pinpoint the reasons why the OD\&EE journal did not manage to attract submissions. We suspect it to be a mix of different contributing factors, including:

- The pre-occupation with citation indexes, and the strong focus on "basket journals" in management sciences, etc., have created a less favorable environment for novel and innovative journals that need to start from scratch.

- From our own experiences in inviting authors to submit papers to OD\&EE, we know that this has certainly been a concern to several younger academics.

Rodrigo Magalhães

rodrigo.magalhaes@inov.pt

Henderik A. Proper

erik.proper@list.lu

1 Centre for Organisation Design and Engineering, INOV, Lisbon, Portugal

2 Luxembourg Institute for Science and Technology, Esch-sur-Alzette, Luxembourg
- At the same time, and we actually consider this to be positive sign, existing journals have been increasing their actual scope, de-facto creating bridges. Examples include: the "Journal of Organization Design" and the "Software and Systems Journal".

- The somewhat misleading and confusing positioning of the Journal as a computer science journal only (necessary for technical reasons in the organization of Springer's web pages), also did not make it easy to attract authors. Clearly, neither Organizational Design, nor Enterprise Engineering, can be thought of as a sub-field of computer science alone, even less so under database management.

In closing, we would like to thank the submitting authors, the reviewers, and board members, who have worked closely with us in trying to make the OD\&EE journal a success. We would also thank Springer for offering the opportunity to try and establish a new journal. We certainly expect to OD\&EE topics to continue being researched and published in the context of existing platforms, such as the Enterprise Engineering book series (https://www.springer.com/series/8371) and events linked to the Advances in Enterprise Engineering proceedings sub-series (https://www.springer.com/gp/book/ 9783319579542), as well as the afore mentioned journals of "Journal of Organization Design" and the "Software and Systems Journal”. 